\title{
OPTIMIZATION OF ULTRASOUND-ASSISTED EXTRACTION OF POLYPHENOLS FROM GLOBE ARTICHOKE (CYNARA SCOLYMUS L.) BRACTS RESIDUES USING RESPONSE SURFACE METHODOLOGY
}

\author{
Miguel Angel Quispe ${ }^{1 凶}$, José Alberto Pacheco Valenzuela², \\ Alex Rubén Huamán de la $\mathrm{Cruz}^{3}$, Clara Raquel Espinoza Silva ${ }^{2}$, \\ Greta Hinostroza Quiñonez ${ }^{2}$, Galia Mavel Manyari Cervantes ${ }^{4}$ \\ ${ }^{1}$ Universidad Nacional del Centro del Perú \\ Mariscal Castilla 3909, El Tambo - Huancayo, Perú \\ ${ }^{2}$ Facultad de Ingeniería en Industrias Alimentarias, Universidad Nacional del Centro del Perú \\ Mariscal Castilla 3909, El Tambo - Huancayo, Perú \\ ${ }^{3}$ Instituto General de Investigación, Universidad Nacional del Centro del Perú \\ Mariscal Castilla 3909, El Tambo - Huancayo, Perú \\ ${ }^{4}$ Facultad de Ciencias de la Salud, Universidad Nacional Autónoma Altoandina de Tarma \\ Jr. Huaraz 431, Tarma, Perú
}

\begin{abstract}
Background. The globe artichoke (Cynara scolymus L.) is a rich source of phenolic compounds which may be extracted by ultrasound technology and used as a medicinal alternative. The objective of this work was to determine the radiation amplitude (\%), ethanol concentration (\%), and time extraction (min) required to guarantee an elevated content of polyphenol compounds.

Materials and methods. The optimal extraction conditions were assessed through the Box-Wilson design and by applying Composite Face Centered (CCFC) and total phenolic compounds (TPC) as the response variables.

Results. A quadratic model was adequate, with $R^{2}=0.993$. The optimal conditions were a radiation amplitude of $97 \%$, an ethanol concentration of $53 \%$, and an extraction time of $9.7 \mathrm{~min}$. The optimized extract of artichoke bracts (Cynara scolymus L.) showed a TPC of $25.13( \pm 0.030) \mathrm{mg}$ GAE/g, an antioxidant activity $\mathrm{DPPH}$ of $39.79( \pm 0.014) \mathrm{mmol}$ Trolox equivalents (TE), and an antioxidant capacity TEAC of $33.98( \pm 0.03)$ mmol Trolox equivalents.

Conclusion. The results showed values closely related to the expected values, indicating that the models were well-developed.
\end{abstract}

Keywords: extraction, ultrasound, optimization, polyphenols, antioxidant capacity

\footnotetext{
This project was funded with the Canon, Sobrecanon, and Mining Royalties Funds 348 administered by the National University of Central Peru with Resolution no. 1565-R-2017 as 349 part of the project "Evaluation of hypoglycemic properties in in vitro models of 350 nano encapsulated of polyphenols from artichoke residues (Cynara scolymus L.)".
}

凶quispe_miguelangel@hotmail.com 


\section{INTRODUCTION}

The globe artichoke (Cynara scolymus L.) is a perennial herbaceous plant that originated from Mediterranean countries, but is also widely cultivated worldwide (Frutos et al., 2019; Zhang and Cao, 2015). The annual production of artichokes in some countries is as follows: Italy (about 458,890 t annually), Spain (239,846 t), Egypt (152,909 t), Argentina (92,672 t), and Peru (71,540 t) (FAOSTAT, 2018). In Peru, artichokes are cultivated mainly in the regions of Lima, La Libertad, Ica, Ayacucho, Huancavelica, and Junín (known as Mantaro Valley). The edible parts consist of large immature inflorescences, called capitula or heads (Kollia et al., 2017; Sałata et al., 2012). During industrial processing, about $60-85 \%$ of artichokes harvested are discarded (Noriega-Rodríguez et al., 2020). Artichoke waste basically consists of leaves, stems, and mainly of the external parts of the heads (known as bracts) (Noriega-Rodríguez et al., 2020). These residues generate a great economic loss and environmental contamination because they are not suitable for human consumption and are discarded into the environment. However, they may be recovered due to the fact that they are rich sources of bioactive phenolic compounds, fiber, inulin, and minerals necessary for human nutrition (Jiménez-Moreno et al., 2019; Ruiz-Cano et al., 2014). As well as this, many studies have shown that artichokes have important medicinal properties such as antioxidant, diuretic, antifungal, antibacterial, and anticarcinogenic effects, as well as aiding cholesterol reduction and weight loss and helping to prevent a wide range of disorders and degenerative diseases, etc., (D'Antuono et al., 2018; Mahboubi, 2018; Salem et al., 2015). These health benefits from artichoke consumption are primarily due to its content of polyphenols. Artichoke composition depends on many factors such as climate, the variety of artichoke, and harvest time. However, phenolic compounds such as hydroxycinnamic acids and flavonoids are found in abundance in this plant and its waste (Negro et al., 2012). For instance, Zuorro et al. (2016) found higher amounts of polyphenols in artichoke residues than in coffee and grape residues. Therefore, polyphenol extraction/recovery from artichoke waste represents a very important source of this useful resource due to its store quantity and beneficial effects on human health.
Since processes involving the use of several organic solvents (solvent extractor) are known for their undesirable environmental and biological negative impacts, new eco-friendly alternatives for the processing of substances are required. Extraction assisted by ultrasound methods is not harmful and is used in food technology to recovery high amounts of bioactive compounds like polyphenols in a shorter time and at a cheaper cost (Chemat et al., 2011). Several authors have successfully applied this technique to recover polyphenols from different byproducts such as grapes (Carrera et al., 2012), spinaches (Altemimi et al., 2015), peaches, pumpkins (Altemimi et al., 2016), artichokes (Kollia et al., 2017; Rabelo et al., 2016), and coffee beans (Al-Dhabi et al., 2017).

In Perú, the most important artichoke variety is the "Talpiot" and "A-106" in coastal regions, and the "green globe" and "imperial star" in the region of JunínConcepcion. The last two varieties are of a high quality and have an important economic impact within the Mantaro Valley of Huancayo. However, the industries that are currently processing this plant produce about 7171 metric tons (MT) per hectare by year, of which 4302 MT are discarded as waste, with a corresponding negative environmental impact and economic loss for producers (Flores and Villanueva, 2019). The green globe artichoke is a newly improved artichoke with a good harvest of 3-4 heads, and the imperial star is a sweeter hybrid and can produce $6-8$ heads per season.

Thus, the objective of this study was to optimize the ultrasound-assisted extraction (UAE) of total polyphenol compounds from artichoke bracts waste using response surface methodology.

\section{EXPERIMENTAL PROCEDURE}

\section{Reagents and samples}

Analytical standards of gallic acid, sodium carbonate, Folin-Ciocalteu, 2.2-diphenyl-1-picrylhyrazyl (DPPH), methanol, 6-hydroxy-2,5,7,8-tetramethyl chroman-2-carboxylic, 2.2-azino-bis (3-ethylbenzothiazoline-6-sulfonic acid) refers to ABTS, and only potassium persulfate was purchased from Sigma-Aldrich (Lima, Peru). The external bracts of the artichokes used in this study were the Cynara scolymus L., provided by a local producer from Concepcion between May and July of 2019. Conception Province is located 
at $3283 \mathrm{~m}$ a.s.l. in the Junín Region, Peru. The bract (fresh artichokes) samples were lyophilized (model Biobase, BK-FD10PT, Shandong, China), grounded (Model M20-S000, KIKA WERKE, Argentina), sieved $(500 \mu \mathrm{m}$ mesh), and stored in dry and closed recipients.

\section{Extracts}

Ultrasound-assisted extraction (UAE) was used to obtain the extracts using a Kisker 053275 (Kisker Ultrasonic, Steinfurt, Germany) ultrasound tank (with a tank capacity of $1.4 \mathrm{~L}$, frequency $42 \mathrm{kHz}$, and $230 \mathrm{~V}$ ). Ethanol was employed as an extraction solvent. For each extract, approximately $1 \mathrm{~g}$ of powder sample was placed into a $100 \mathrm{~mL}$ Erlenmeyer flask and the corresponding solvent mixture ( $5 \mathrm{ml}$ water : $5 \mathrm{~mL}$ ethanol) was added. The Erlenmeyer flask containing the solution was submitted to ultrasound following the conditions established by the design response surface. The obtained mixtures were centrifuged at $400 \mathrm{rpm}$ for 15 minutes, filtered through Whatman paper no. 1 (100-200 mbar) stored in amber glass bottles under vacuum conditions, and refrigerated at $-5^{\circ} \mathrm{C}$ until use. All analyses were performed on consecutive days to avoid any changes in the samples due to prolonged storage time.

\section{Determination of total phenolic compounds (TPC)}

The determination of total phenols was carried out using the Folin-Ciocalteu method as described by Singleton and Rossi (1965). The assay was performed using a Genesys $10 \mathrm{UV}$-Vis spectrophotometer (Thermo Fisher Scientific, UK). For this, $500 \mu \mathrm{L}$ of the Folin-Ciocalteu reagent and $40 \mu \mathrm{L}$ of each extract were added to a $10 \mathrm{~mL}$ volumetric flask and covered with aluminum foil. Then, after 10 minutes of rest, 500 $\mu \mathrm{L}$ of $10 \% \mathrm{Na}_{2} \mathrm{CO}_{3}$ was added and made up to $10 \mathrm{~mL}$ with ultrapure water. The absorbance was measured at a wavelength of $755 \mathrm{~nm}$ against a blank prepared with $40 \mu \mathrm{L}$ of ultrapure water. In order to quantify this, a calibration curve with six points $(0.1 ; 0.2 ; 0.4 ; 0.5$; 0.6 ; and $0.9 \mathrm{mg} / \mathrm{mL}$ ) of gallic acid in water was prepared. The TPC was expressed in $\mathrm{mg}$ of gallic acid equivalents GAE/g dry sample.

\section{Antioxidant activity}

The measurement of solution density DPPH assay for determination of antioxidant activity was done according to Brand-Williams et al. (1995) and conducted at $515 \mathrm{~nm}$. The DPPH solution was prepared with a mixture of $80 \%$ ethanol and $20 \%$ ultrapure water. This solution was standardized. The absorbance of the samples was recorded at $540 \mathrm{~nm}$ in a spectrophotometer. Quantification was carried out through a calibration curve with six points $(0.1,0.2,0.3,0.5,0.6,0.7$, and 0.8 $\mathrm{mM}$ ) of Trolox in ethanol. The results were expressed in mg of Trolox equivalents (TE)/g dry sample. In all cases, the extracts were measured in triplicate.

\section{Trolox equivalent antioxidant capacity (TEAC)}

The TEAC assay was used to measure the total antioxidant capacity. For this, the ABTS method [ $\left(2,2^{\prime}\right.$-azinobis (3-ethylbenzothiazoline-6-sulphonic acid)) was used based on the method outlined by Rice-Evans et al. (1996). The absorbance was measured at $734 \mathrm{~nm}$ using a UV-Vis spectrophotometer (Thermo Fisher Scientific, UK). The calibration curve was prepared from a $5 \mathrm{mM}$ solution of Trolox ranging from 0.1 to $0.8 \mathrm{mM}$. The results were reported in $\mathrm{mg}$ of Trolox equivalents (TE)/g dry sample.

\section{Equivalent design}

The experiments were carried out using the Box-Wilson design, also called the central composite design (CCD). In CCD, the central composite face-centered (CCFC) includes a total of 17 experiments (consisting of 8-factor points, 6 start points and 3 replicates at the central points to allow estimation of pure error). The three variables studied were the radiation amplitude $\left(X_{1}\right)$, ethanol concentration $\left(X_{2}\right)$, and extraction time $\left(X_{3}\right)$. The number of experiments was computed using equation 1 (Azargohar and Dalai, 2005):

$$
N=2^{n}+2 n+n_{c}
$$

where:

$N$ - the total number of experiments,

$n$ - the number of factors,

$c$ - the number of central points.

Significant variables were analyzed to select the optimal levels of the independent variables and the effect of the independent variable interactions using the composite face-centered (CCFC) from the central composite design (CCD). Table 1 shows the factor level and the central point of the design of the response surface methodology (low, central/medium, high) 
Table 1. Level of variables selected in the factorial design and response surface methodology

\begin{tabular}{lcccc}
\hline & \multicolumn{4}{c}{ Coded variable level } \\
\cline { 2 - 5 } \multicolumn{1}{c}{ Independent variable } & & low & central & high \\
\cline { 2 - 5 } & symbol & -1 & 0 & +1 \\
\hline Radiation amplitude, \% & $X_{1}$ & 80 & 90 & 100 \\
Ethanol concentration, \% & $X_{2}$ & 40 & 50 & 60 \\
Extraction time, min & $X_{3}$ & 5 & 10 & 15 \\
\hline
\end{tabular}

on independent coded variables. The experimental data were adjusted through the second-order polynomial (equation 2):

$\mathrm{Y}=\beta_{0}+\sum_{j=1}^{k} \beta_{j} X_{j}+\sum_{j=1}^{k} \beta_{j J} X_{j}^{2}+\sum_{i} \sum_{<j=2}^{k} \beta_{i j} X_{i} X_{j}+e_{i}$

where:

$$
\begin{array}{ll}
Y & - \text { the predicted response, } \\
\beta_{0} \quad-\text { the intercept, } \\
\beta_{j}, \beta_{i j}, \beta_{i j}- & \text { the regression coefficients for mean, } \\
& \text { linear, interactions, and quadratic terms, } \\
& \text { respectively, } \\
X_{i}, X_{j} \quad- & \text { independent variables or factors ranging } \\
& \text { from }-1 \text { to } 1, \text { and is the error (Maran et } \\
& \text { al., 2013). }
\end{array}
$$

Design-Expert version 12.0 software was employed (Trial version, Stat-Ease, Minneapolis, MN, USA).

\section{Optimization}

Derringer's desirability function method was employed to optimize responses in the UAE process, which uses functions of convenience. The general approach consists of first converting each outcome in an individual desirability function that varies along the scale $(0 \leq d i \leq 1)$. If the outcome is within the acceptable region, $d i=1$. In contrast, $d i=0$. And which are equal to the geometric mean of the individual desirable functions. The design variables are then chosen to maximize desirability through equation 3 (Derringer and Suich, 1980).

$$
D=(d 1 \cdot d 2 \cdot \ldots d m)^{1 / m}
$$

\section{Model validation}

The extraction of phenolic compounds from artichoke waste was optimized, considering amplitude radiation, ethanol concentration, and extraction time as in- dependent variables. Optimal conditions were found by applying the predictive equation of the surface response methodology. The antioxidant activity DPPH was performed after polyphenolic compound extraction under optimal conditions (equation 3). Finally, the experimental and predicted values were compared to determine the validity of the model.

\section{Statistical analysis}

The coefficient values of adjusted $R^{2}$ and predicted $R^{2}$ and the coefficient of variation $(\mathrm{CV}, \%)$ were evaluated to validate the model. The validity of each test series was checked, and the model validity was assessed by ANOVA to assess the relevance of the independent variables' influence and interactions $(P<0.05)$. The model validity was determined through the coefficient of determination $\left(R^{2}\right)$, the significance $(p)$, and the lack of adjustment test.

\section{RESULTS AND DISCUSSIONS}

\section{Determination of process parameters in the extraction and adjustment of the model}

Radiation amplitude $\left(X_{1}, \%\right)$, ethanol concentration $\left(X_{2}\right.$, $\%)$, and extraction time ( $X_{3}$, minutes) were assessed and their conditions varied in an ultrasound-assisted extraction to observe the effects on total phenolic compound (TPC), antioxidant activity (DPPH), and the Trolox equivalent antioxidant capacity (TEAC) (Table 2). The results in Table 2 show that the TPC ranged from 10.86 to $24.82 \mathrm{mg} \mathrm{GAE} / \mathrm{g}$, DPPH between 15.49 and $8.65 \mathrm{mM}$ Trolox, and the TEAC from 12.56 to $32.52 \mathrm{mM}$ Trolox.

Multiple regression analysis was applied to evaluate the adequate development of the model, and variance analysis (ANOVA) was used to assess the relevance of the independent variable's influence and interactions $(p<0.05)$. The probabilities of the significance of the effects analyzed in ANOVA and response variables are shown in Table 3 . These values were recalculated excluding non-significant variables to obtain adjusted coefficients for the model. In Table 3, it can be observed that Fisher's $F$ test values for TPC, DPPH, and TEAC were 100.93, 59.85, and 83.3 respectively, which are considered extremely high. In addition, a low $p<0.0001$ value was produced, indicating that the model was highly significant. 
Quispe, M. A., Valenzuela, J. A. P., de la Cruz, A. R. H., Silva, C. R. E., Quiñonez, G. H., Cervantes, G. M. M. (2021). Optimization of ultrasound-assisted extraction of polyphenols from globe artichoke (Cynara scolymus L.) bracts residues using response surface methodology. Acta Sci. Pol. Technol. Aliment., 20(3), 277-290. http://dx.doi.org/10.17306/J.AFS.2021.0937

Table 2. Composite face-centered (CCF) design from the three factors, three levels, and response observations under different experimental conditions

\begin{tabular}{crrrccc}
\hline & \multicolumn{3}{c}{ Extraction conditions } & & \multicolumn{3}{c}{ Responses } \\
\cline { 2 - 6 } Experiment & $X_{1}$ & $X_{2}$ & $X_{3}$ & $\begin{array}{c}\text { TPC } \\
\text { mg GAE } / \mathrm{g}\end{array}$ & $\begin{array}{c}\text { DPPH } \\
\text { mM TE }\end{array}$ & $\begin{array}{c}\text { TEAC } \\
\text { mM TE }\end{array}$ \\
\hline 1 & $\%$ & 50 & 10 & 24.28 & 38.42 & 31.37 \\
2 & 90 & 50 & 10 & 23.92 & 37.68 & 32.28 \\
3 & 90 & 40 & 15 & 15.91 & 24.20 & 21.87 \\
4 & 80 & 60 & 10 & 20.72 & 31.22 & 29.82 \\
5 & 90 & 60 & 15 & 16.59 & 26.24 & 22.48 \\
6 & 80 & 10 & 16.13 & 24.52 & 20.57 \\
7 & 90 & 10 & 24.82 & 38.65 & 32.52 \\
8 & 90 & 50 & 5 & 22.99 & 34.39 & 28.39 \\
9 & 100 & 60 & 10 & 23.73 & 36.93 & 31.82 \\
10 & 100 & 50 & 15 & 22.04 & 34.76 & 29.64 \\
11 & 90 & 50 & 15 & 19.89 & 31.05 & 26.28 \\
12 & 100 & 60 & 5 & 15.85 & 24.88 & 21.56 \\
13 & 80 & 60 & 15 & 14.60 & 23.50 & 20.82 \\
14 & 100 & 40 & 5 & 22.04 & 34.00 & 28.41 \\
15 & 90 & 50 & 50 & 21.77 & 32.37 & 28.89 \\
16 & 80 & 50 & 50 & 10.87 & 15.50 & 12.57 \\
17 & 100 & 40 & 12.58 & 19.80 & 16.25 \\
\hline
\end{tabular}

$X_{1}$ - radiation amplitude, $X_{2}$ - ethanol concentration, $X_{3}$ - extraction time, TPC - total phenolic compounds, DPPH - Trolox equivalent antioxidant activity, TEAC.

The determination coefficient $R^{2}$ for TPC was 0.992, 0.987 for DPPH, and 0.991 for TEAC, which suggested a satisfactory correlation between the experimental and predicted values.

The Adj $R$-squared for TPC was 0.983 , which meant that most of the TPC variations $(>99 \%)$ could be predicted by the model, while only $3 \%$ could not. Likewise, the DPPH showed an Adj $R$-squared of 0.971, and the TEAC presented an Adj $R$-squared of 0.979 . The lack of fit of the model was not significant. The $F$ value of 1.92 and the $p$-value of 0.3775 for TPC suggested that the lack of adjustment was negligible concerning pure error due to noise. Similar results were found in DPPH $(F$ value $=7.38$ and $p$-value $=0.1237)$, and TEAC $(F$ value $=2.48$ and $p$-value $=0.311)$.
Lower values of the coefficient of variation (CV) for TCP (3.02\%), DPPH (4.00\%), and TEAC (3.39\%) were found, clearly indicating that deviations between experimental and predicted values showed a high degree of accuracy and precision in the experiments. Our results found a signal-to-noise ratio of 29.77 for TCP, 23.98 for DPPH, and 29.09 for TEAC, confirming that this model can be used to navigate the design space.

The optimization of the extraction process was determined by applying the second-order polynomial equations (equation 4,5 , and 6 ), which were used to generate graphical representations of regression equation simulated by the Design-Expert Software that were represented through 3D response surface (Fig. 1, 2 , and 3 ). 
Quispe, M. A., Valenzuela, J. A. P., de la Cruz, A. R. H., Silva, C. R. E., Quiñonez, G. H., Cervantes, G. M. M. (2021). Optimization of ultrasound-assisted extraction of polyphenols from globe artichoke (Cynara scolymus L.) bracts residues using response surface methodology. Acta Sci. Pol. Technol. Aliment., 20(3), 277-290. http://dx.doi.org/10.17306/J.AFS.2021.0937

Table 3. ANOVA of the response surface quadratic polynomial model for TPC, DDPH, and TEAC

\begin{tabular}{|c|c|c|c|c|c|c|}
\hline Source & Sum of squares & DF & Mean square & $F$-value & $p$-value & Prob $>F$ \\
\hline 1 & 2 & 3 & 4 & 5 & 6 & 7 \\
\hline \multicolumn{7}{|c|}{ TPC } \\
\hline Model & 310 & 9 & 34.5 & 101 & $<0.0001$ & $* * *$ \\
\hline$X_{1}$-amplitude & 16.4 & 1 & 16.4 & 47.9 & 0.0002 & $* *$ \\
\hline$X_{2}$-ethanol & 67.3 & 1 & 67.3 & 197 & $<0.0001$ & $* * *$ \\
\hline$X_{3}$-time & 2.2 & 1 & 2.2 & 6.5 & 0.038 & $*$ \\
\hline$X_{1} X_{2}$ & 12.6 & 1 & 12.6 & 36.9 & 0.001 & $*$ \\
\hline$X_{1} X_{3}$ & 5.9 & 1 & 5.9 & 17.4 & 0.004 & $*$ \\
\hline$X_{2} X_{3}$ & 11.1 & 1 & 11.1 & 32.5 & 0.001 & $* *$ \\
\hline$X_{1}^{\wedge} 2$ & 2.4 & 1 & 2.4 & 7.1 & 0.032 & $*$ \\
\hline$X_{2}^{\wedge} 2$ & 74.5 & 1 & 74.5 & 218 & $<0.001$ & $* * *$ \\
\hline$X_{3}^{\wedge} 2$ & 7.4 & 1 & 7.4 & 21.6 & 0.0024 & $* *$ \\
\hline Residual & 2.4 & 7 & 0.3 & \multirow{11}{*}{1.9} & \multirow{11}{*}{0.38} & \multirow{11}{*}{ NS } \\
\hline Lack of fit & 1.9 & 5 & 0.4 & & & \\
\hline Pure error & 0.4 & 2 & 0.2 & & & \\
\hline Cor total & 312 & 16 & & & & \\
\hline Std. dev. & 0.6 & & & & & \\
\hline Mean & 19.3 & & & & & \\
\hline $\mathrm{CV}, \%$ & 3.0 & & & & & \\
\hline$R$-squared & 1.0 & & & & & \\
\hline Adj $R$-squared & 0.9 & & & & & \\
\hline Pred $R$-squared & 0.9 & & & & & \\
\hline Adeq precision & 29.8 & & & & & \\
\hline \multicolumn{7}{|c|}{ DPPH } \\
\hline Model & 769 & 9 & 85.5 & 59.9 & $<0.0001$ & $* * *$ \\
\hline$X_{1}$-amplitude & 50.5 & 1 & 50.5 & 35.4 & 0.0006 & $* *$ \\
\hline$X_{2}$-ethanol & 162 & 1 & 162 & 114 & $<0.0001$ & $* * *$ \\
\hline$X_{3}$-time & 12.5 & 1 & 12.5 & 8.8 & 0.0211 & $* *$ \\
\hline$X_{1} X_{2}$ & 14.4 & 1 & 14.4 & 10.1 & 0.0156 & * \\
\hline$X_{1} X_{3}$ & 11.8 & 1 & 11.8 & 8.2 & 0.0240 & $*$ \\
\hline$X_{2} X_{3}$ & 25.8 & 1 & 25.8 & 18.1 & 0.0038 & $* *$ \\
\hline$X_{1}^{\wedge} 2$ & 8.7 & 1 & 8.7 & 6.1 & 0.0426 & $*$ \\
\hline$X_{2}^{\wedge} 2$ & 198 & 1 & 198 & 138 & $<0.0001$ & $* * *$ \\
\hline$X_{3}^{\wedge} 2$ & 11.6 & 1 & 11.6 & 8.1 & 0.025 & $* *$ \\
\hline
\end{tabular}


Quispe, M. A., Valenzuela, J. A. P., de la Cruz, A. R. H., Silva, C. R. E., Quiñonez, G. H., Cervantes, G. M. M. (2021). Optimization of ultrasound-assisted extraction of polyphenols from globe artichoke (Cynara scolymus L.) bracts residues using response surface methodology. Acta Sci. Pol. Technol. Aliment., 20(3), 277-290. http://dx.doi.org/10.17306/J.AFS.2021.0937

Table 3 - cont.

\begin{tabular}{|c|c|c|c|c|c|c|}
\hline 1 & 2 & 3 & 4 & 5 & 6 & 7 \\
\hline Residual & 10.0 & 7 & 1.4 & \multirow{11}{*}{7.38} & \multirow{11}{*}{0.124} & \multirow{11}{*}{ NS } \\
\hline Lack of fit & 9.5 & 5 & 1.9 & & & \\
\hline Pure error & 0.5 & 2 & 0.3 & & & \\
\hline Cor total & 779 & 16 & & & & \\
\hline Std. dev. & 1.2 & & & & & \\
\hline Mean & 29.9 & & & & & \\
\hline $\mathrm{CV}, \%$ & 4.0 & & & & & \\
\hline$R$-squared & 0.9 & & & & & \\
\hline $\operatorname{Adj} R$-squared & 0.9 & & & & & \\
\hline Pred $R$-squared & 0.9 & & & & & \\
\hline Adeq precision & 23.9 & & & & & \\
\hline \multicolumn{7}{|c|}{ TEAC } \\
\hline Model & 566 & 9 & 62.8 & 83.3 & $<0.0001$ & $* * *$ \\
\hline$X_{1}$-amplitude & 26.3 & 1 & 26.3 & 34.8 & 0.0006 & $* *$ \\
\hline$X_{2}$-ethanol & 133 & 1 & 133 & 176 & $<0.0001$ & $* * *$ \\
\hline$X_{3}$-time & 19.3 & 1 & 19.3 & 25.6 & 0.0015 & $* *$ \\
\hline$X_{1} X_{2}$ & 8.0 & 1 & 8.0 & 10.6 & 0.0140 & $*$ \\
\hline$X_{1} X_{3}$ & 7.5 & 1 & 7.5 & 9.9 & 0.0160 & $*$ \\
\hline$X_{2} X_{3}$ & 28.4 & 1 & 28.4 & 37.6 & 0.0005 & $* *$ \\
\hline$X_{1}^{\wedge} 2$ & 5.1 & 1 & 5.1 & 6.8 & 0.0354 & $*$ \\
\hline$X_{2}^{\wedge} 2$ & 115 & 1 & 115 & 152 & $<0.0001$ & $* * *$ \\
\hline$X_{3}^{\wedge} 2$ & 19.7 & 1 & 19.7 & 26.1 & 0.0014 & $* *$ \\
\hline Residual & 5.3 & 7 & 0.8 & & & \\
\hline Lack of fit & 4.6 & 5 & 0.9 & 2.5 & 0.3114 & NS \\
\hline Pure error & 0.7 & 2 & 0.4 & & & \\
\hline Cor total & 571 & 16 & & & & \\
\hline Std. dev. & 0.9 & & & & & \\
\hline Mean & 25.6 & & & & & \\
\hline $\mathrm{CV}, \%$ & 3.4 & & & & & \\
\hline$R$-squared & 0.99 & & & & & \\
\hline Adj $R$-squared & 0.98 & & & & & \\
\hline Pred $R$-squared & 0.93 & & & & & \\
\hline Adeq precision & 29.1 & & & & & \\
\hline
\end{tabular}

$X_{1}$ - radiation amplitude, $X_{2}$ - ethanol concentration, $X_{3}$ - extraction time, TPC - total phenolic content, DPPH - antioxidant activity, TEAC - antioxidant capacity in Trolox equivalent (TE). Significance level: ${ }^{* *} p \leq 0.001,{ }^{* *} p \leq 0.01,{ }^{*} p \leq 0.05,0.05 \leq{ }^{\mathrm{fcs}} p \leq$ 0.1 (factor considered significant (Rezende et al., 2017)), nsp $>0.1$ (not significant). 


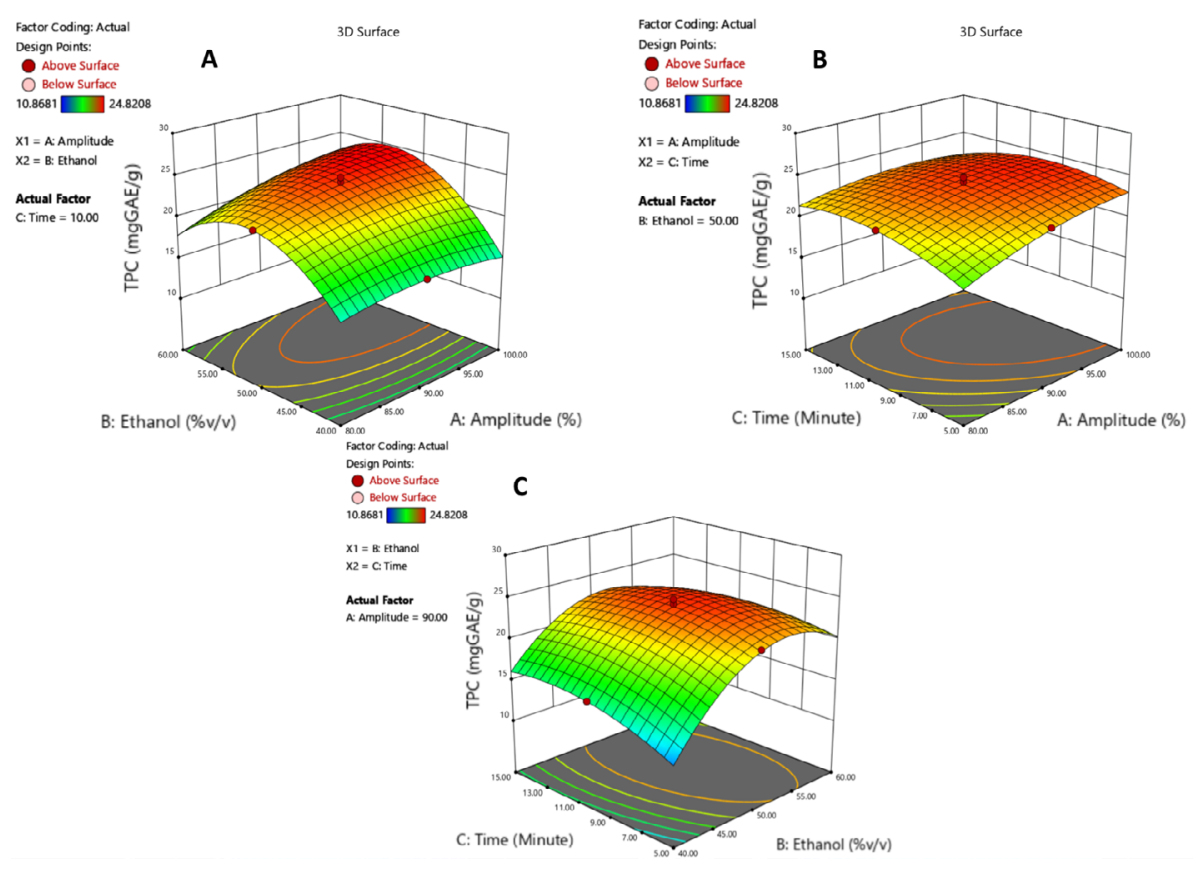

Fig. 1. Response surface graph (3D) from total phenolic compounds (TPC) based on the interaction significance between factors: $\mathrm{A}$ - radiation amplitude and ethanol concentration, $\mathrm{B}$ - ethanol concentration and extraction time, $\mathrm{C}$ - radiation amplitude and extraction time

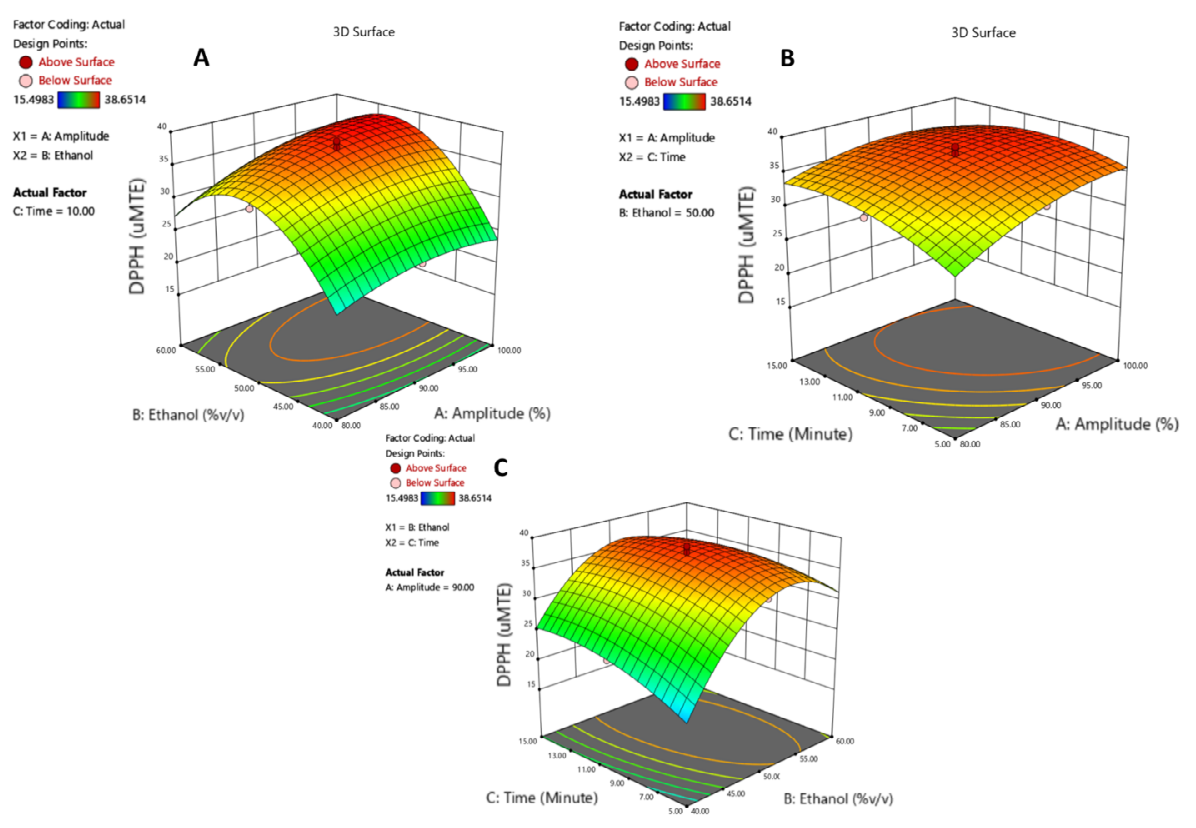

Fig. 2. Response surface graph (3D) from the radical removal activity DPPH based on the interaction significance between factors: $\mathrm{A}$ - radiation amplitude and ethanol concentration, $\mathrm{B}$ - ethanol concentration and extraction time, $\mathrm{C}$ - radiation amplitude and extraction time 


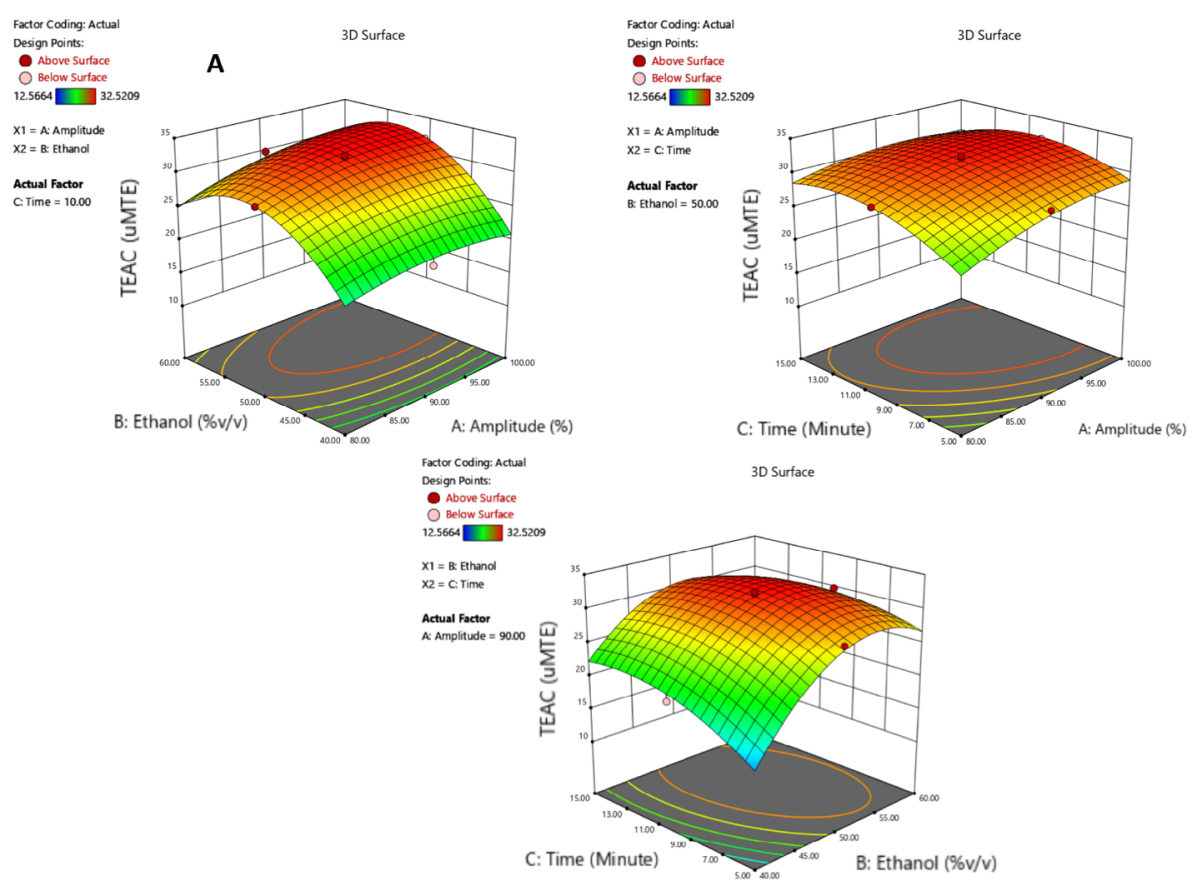

Fig. 3. Response surface graph (3D) from the Trolox equivalent antioxidant capacity (TEAC) based on the interaction significance between factors: $\mathrm{A}$ - radiation amplitude and concentration of ethanol, $\mathrm{B}$ - concentration of ethanol and time, $\mathrm{C}$ - radiation amplitude and extraction time

\section{Effects of the variables on ultrasound-assisted extraction (UAE)}

Total phenolic compounds (TPC). The total phenolic compounds of the artichoke bracts ranged from $10.86 \mathrm{mg}$ to $24.82 \mathrm{mg} \mathrm{GAE} / \mathrm{g}$ (Table 2). Zuorro et al. $(2014 ; 2016)$ reported similar results from total polyphenol content in bracts $(24.14 \mathrm{mg} \mathrm{GAE} / \mathrm{g}$ ) using a 50:50 ethanol-water mixture as an efficient extraction method. Likewise, Mena-García et al. (2020) applying a microwave-assisted extraction and ethanol: water $(50: 50, \mathrm{v} / \mathrm{v})$ as an extraction solution found that the total polyphenol content was between 9-18 $\mathrm{mg} \mathrm{GAE} / \mathrm{g}$ in bracts from artichoke residues. In contrast, Kollia et al. (2017) reported lower values of total phenolic content (TPC) in different parts (heads $(0.49$ $\pm 0.03 \mathrm{mg} \mathrm{GAE} / \mathrm{g})$, bracts $(0.41 \pm 0.01 \mathrm{mg} \mathrm{GAE} / \mathrm{g})$ and stems (0.33 $\pm 0.01 \mathrm{mg} \mathrm{GAE} / \mathrm{g}))$ of artichokes using ultrasound-assisted extraction.

The interaction between the variables for the total phenolic content $X_{1} X_{2}$ was statistically significant with positive effects, while the terms $X_{1} X_{3}$, and $X_{2} X_{3}$ had a statistically significant but negative effect on the performance of the TPC at $99 \%$. The second-degree terms $X_{12}, X_{22}$, and $X_{23}$ increased the negative effect on TPC with a significance level of $95 \%$.

The effect of the radiation amplitude of ultrasound power on the extraction process showed a direct effect on the polyphenol content. An increase in radiation amplitude from ultrasound facilitates cell wall rupture, increases solubility, elevates the extraction performance efficiency (Kollia et al., 2017; Maran, 2017), increases the release of specific compounds (Soria and Villamiel, 2010), and may also increase eco-chemical effects (Chemat et al., 2017). Likewise, changes in the concentration of ethanol may modify the physical properties of the solvent such as density, dynamic viscosity, and dielectric constant, as well as modifying the solubilities that influence phenolic extraction (Chaves et al., 2020).

The extraction time is also associated with input power improving the ultrasound extraction (Chemat et al., 2017). However, a longer extraction time with 
ultrasound treatment could induce polyphenol degradation through equation 4 (Tiwari et al., 2009).

$$
\begin{gathered}
\text { Phenols }=23.97+1.28 X_{1}+2.59 X_{2}+0.47 X_{3}+ \\
12.6 X_{1} X_{2}-0.86 X_{1} X_{3}-1.18 X_{2} X_{3}-0.95 X_{1}^{2}- \\
5.27 X_{2}^{2}-1.66 X_{3}^{2}
\end{gathered}
$$

Antioxidant activity (DPPH) and Trolox equivalent antioxidant capacity (TEAC). The radical removal activity DPPH and Trolox equivalent antioxidant capacity (TEAC) in bracts from artichoke waste ranged from $15.49 \mathrm{mM}$ Trolox to $38.65 \mathrm{mM}$ Trolox and 12.56 $\mathrm{mM}$ Trolox to $32.52 \mathrm{mM}$ Trolox, respectively. Mena-García et al. (2020) reported similar results of DPPH (26.59 $\pm 0.62 \mathrm{mg} \mathrm{TE} / \mathrm{g}$ ) using a mixture of ethanol/ water $(50: 50 \mathrm{v} / \mathrm{v})$ and a microwave-assisted extraction from the artichoke. However, lower values of DPPH (bracts $(0.11 \pm 0.04 \mathrm{mg} \mathrm{TE} / \mathrm{g}))$ and TEAC (bracts $(0.66$ $\pm 0.10 \mathrm{mg} \mathrm{TE} / \mathrm{g})$ ) from artichoke waste using ultrasound-assisted extraction were reported by Kollia et al. (2017).

Statistical analysis shows that all variables were influential in the antioxidant activity DPPH and Trolox antioxidant capacity equivalent (TEAC) and had a significant effect on the significance level of $95 \%$. The interaction terms for the phenolic content $X_{1} X_{2}$ were statistically significant and with positive effects, while the terms $X_{1} X_{3}$ and $X_{2} X_{3}$ were significant but with a negative effect on the performance of TPC at $99 \%$. The second-degree terms $X_{12}, X_{22}$, and $X_{32}$ harmed the total phenolic content with a significance level of $95 \%$. This is important in the antioxidant capacity of the polyphenols due to the ability to donate hydrogens to form stable radicals (Scalbert et al., 2005). Similar effects of the variables on TEAC and TPC was observed. Zhang et al. (2011) reported a positive correlation $(R=0.98, p<0.001)$ between the total polyphenol content with the oxygen of the radical absorption capacity (ORAC) assay. Sun and Ho (2005) similarly reported that the antioxidant activity determined using the 2.2-diphenyl-1-picrilhyl (DPPH) method in extracts and total polyphenol content had a positive correlation $(R=0.97, p<0.002)$. These results indicate that the total polyphenol content contributes to the antioxidant activity DPPH and the Trolox antioxidant capacity equivalent (TEAC). The radiation amplitude applied to the ultrasound-assisted extraction process showed a better performance during the extraction of polyphenols. Zardo and Espíndola (2017) used ultrasound-assisted extraction and concluded that extraction performance depends on the nature of plant material.

The main effects related to improving releases of plant material content can be attributed to cavitation, which causes cell wall disruption, particle size reduction, intensification of plant material transfer mass, and consequently, an increase in the extraction (Wang and Weller, 2006). The results obtained showed that the optimal concentration of ethanol was equal to $50 \%$ for antioxidant capacity (Table 2).

This concentration was found within the values reported by Maran (2017) for polyphenol performance and antioxidant capacity from artichoke residues extracted using ultrasound.

The use of hydro-alcoholic ethanol mixtures was raised in this study because several authors agree that it is one of the most suitable systems for extraction thanks to the different polarities of the polyphenols and the acceptability of this system for human consumption (Alonso-Riaño et al., 2020). The performance of antioxidant activity DPPH and Trolox antioxidant capacity equivalent (TEAC) increased when the time remained between 5 and 10 minutes but decreased slowly when the time continued to extend (Fig. 2B and 3B). Most polyphenols in broken cells were released in the initial period of 10 minutes due to ultrasound improving the release. Besides this, the number of micro-bubbles created by ultrasound increased as the time extended (>10 minutes), which could undermine surfaces and damage the substance in solution. The structure of the polyphenols and the antioxidant capacity were destroyed, thus their stability decreased due to the continued collapse of microbubbles (Maran et al., 2018).

Determination and validation of optimal conditions. Derringer's function methodology through model equations to predict optimal response values was tested under the following conditions: radiation amplitude to $95 \%$, ethanol concentration at $53 \%$, and an extraction time of 9.7 minutes. The experiments were carried out under optimal conditions to compare the experimental results with the predicted values through the empirical equations developed (equations 4,5 , and 6). 


$$
\begin{gathered}
\mathrm{DPPH}=37.23+2.25 X_{1}+4.03 X_{2}+1.12 X_{3}+ \\
1.34 X_{1} X_{2}-1.21 X_{1} X_{3}-1.80 X_{2} X_{3}-1.81 X_{1}^{2}- \\
8.59 X_{2}^{2}-2.08 X_{3}^{2} \\
\mathrm{ABTS}=31.87+1.62 X_{1}+3.65 X_{2}+1.39 X_{3}+ \\
1.00 X_{1} X_{2}-0.97 X_{1} X_{3}-1.88 X_{2} X_{3}-1.38 X_{1}^{2}- \\
6.54 X_{2}^{2}-2.71 X_{3}
\end{gathered}
$$

The experiments were conducted in triplicate and average values are shown in Table 4 . These values
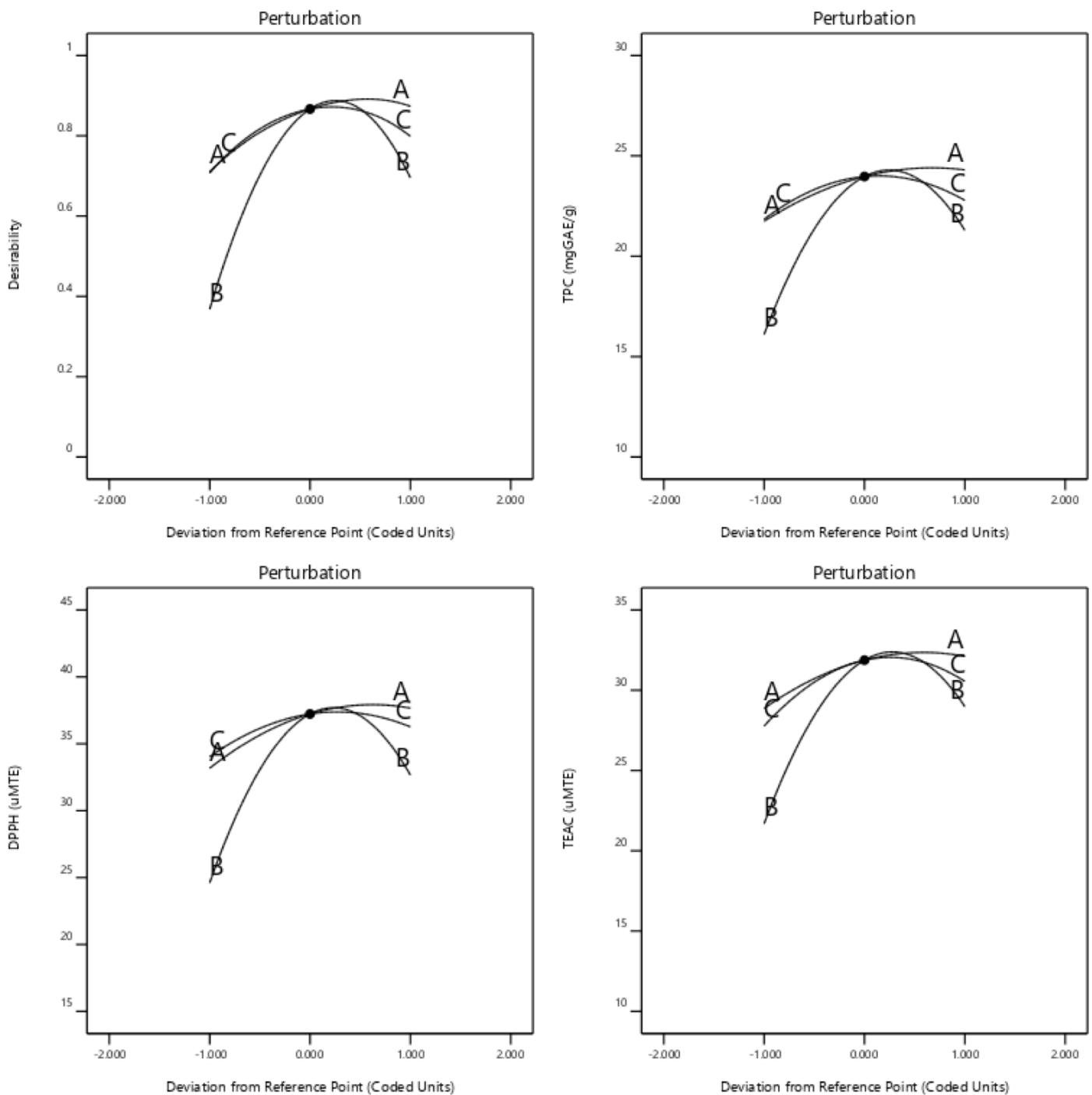

obtained from TPC, DPPH, and TEAC were compared with the predicted values. The experimental values were found to be similar to the predicted values and indicated the suitability of the developed quadratic models (Fig. 4). The optimal results found were 25.13 $\pm 0.030 \mathrm{mg} \mathrm{GAE} / \mathrm{g}$ for TPC, $39.79 \pm 0.014 \mathrm{mM}$ TE for $\mathrm{DPPH}$, and $33.98 \pm 0.03 \mathrm{mM}$ TE for Trolox equivalent antioxidant capacity (TEAC) (Table 4).

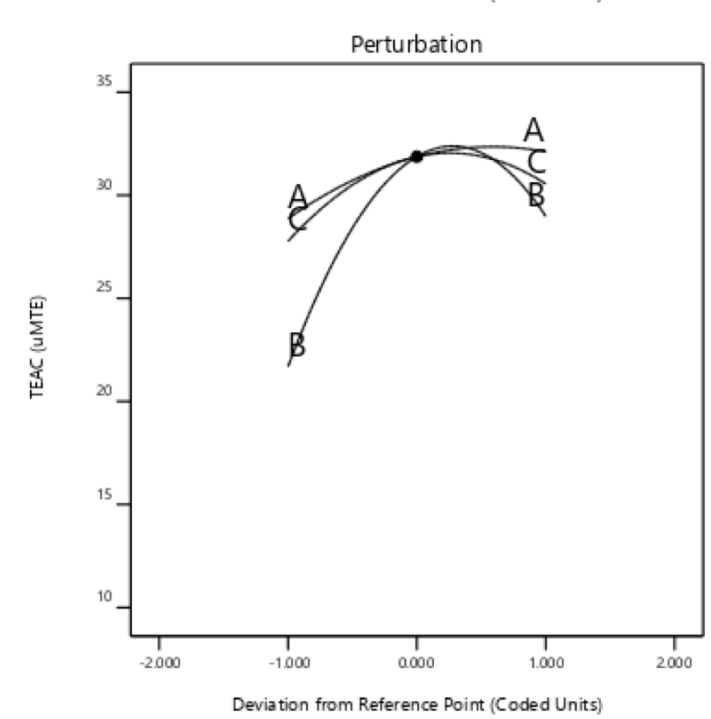

Fig. 4. Desirability function for the abundance of total phenolic compounds (TPC), radical removal activity $\mathrm{DPPH}$, and the Trolox equivalent antioxidant capacity (TEAC) of the extracts from artichoke residues in function of radiation amplitude, $\%$, ethanol concentration, $\% \mathrm{v} / \mathrm{v}$, and time extraction, $\min$ 
Quispe, M. A., Valenzuela, J. A. P., de la Cruz, A. R. H., Silva, C. R. E., Quiñonez, G. H., Cervantes, G. M. M. (2021). Optimization of ultrasound-assisted extraction of polyphenols from globe artichoke (Cynara scolymus L.) bracts residues using response surface methodology. Acta Sci. Pol. Technol. Aliment., 20(3), 277-290. http://dx.doi.org/10.17306/J.AFS.2021.0937

Table 4. Predicted and experimental values based on optimal conditions

\begin{tabular}{lcccccc}
\hline & \multicolumn{3}{c}{ Predicted } & \multicolumn{3}{c}{ Experimental } \\
\cline { 2 - 6 } Optimum \\
\cline { 2 - 6 } levels & $\begin{array}{c}\text { TPC } \\
\text { mg GAE/g } \\
\text { bracts }\end{array}$ & $\begin{array}{c}\text { DPPH } \\
\text { mM TE }\end{array}$ & $\begin{array}{c}\text { TEAC } \\
\text { mM TE }\end{array}$ & $\begin{array}{c}\text { TPC } \\
\text { mg GAE/g } \\
\text { bracts }\end{array}$ & $\begin{array}{c}\text { DPPH } \\
\text { mM TE }\end{array}$ & $\begin{array}{c}\text { TEAC } \\
\mathrm{mM} \mathrm{TE}\end{array}$ \\
\hline$X_{1}=97 \%$ & 25.0 & 38.6 & 33.0 & $25.13 \pm 0.03$ & $39.79 \pm 0.01$ & $33.98 \pm 0.03$ \\
$X_{2}=53 \%$ & & & & & & \\
$X_{3}=9.7$ min & & & & & & \\
\hline
\end{tabular}

TPC, DPPH, and TEAC are expressed as a mean of three determinations \pm standard deviation (SD).

\section{CONCLUSION}

The CCFC design was successfully used to optimize and study the individual and interactive effects of ultrasound-assisted extraction (UAE) process variables, showing values closely related to the expected values, which demonstrates the suitability and validation of the models. Through the analysis of surface response methodology, the factor levels which provide the maximum theoretical content were a radiation amplitude of $97 \%$, an ethanol concentration of $53 \%$, and an extraction time of $9.7 \mathrm{~min}$. The polynomial model presented the best fit with an $R^{2}$ value of $0.992,0.987$, and 0.991 for TPC, DPPH, and TEAC, respectively. The results were validated experimentally reaching values similar to those that were predicted. Therefore, these results provide valuable information on the extraction process referred to as antioxidant phenols in artichoke bract extract.

\section{REFERENCES}

Al-Dhabi, N. A., Ponmurugan, K., Maran Jeganathan, P. (2017). Development and validation of ultrasoundassisted solid-liquid extraction of phenolic compounds from waste spent coffee grounds. Ultrason. Sonochem., 34, 206-213. https://doi.org/10.1016/j.ultsonch. 2016.05.005

Alonso-Riaño, P., Diez, M. T. S., Blanco, B., Beltrán, S., Trigueros, E., Benito-Román, O. (2020). Water ultrasound-assisted extraction of polyphenol compounds from brewer's spent grain: Kinetic study, extract characterization, and concentration. Antioxidants, 9(3). https:// doi.org/10.3390/antiox9030265
Altemimi, A., Choudhary, R., Watson, D. G., Lightfoot, D. A. (2015). Effects of ultrasonic treatments on the polyphenol and antioxidant content of spinach extracts. Ultrasonics Sonochem., 24, 247-255. https://doi. org/10.1016/j.ultsonch.2014.10.023

Altemimi, A., Watson, D. G., Choudhary, R., Dasari, M. R., Lightfoot, D. A. (2016). Ultrasound assisted extraction of phenolic compounds from peaches and pumpkins. PLoS ONE, 11(2), e0148758. https://doi.org/10.1371/ journal.pone.0148758

Azargohar, R., Dalai, A. K. (2005). Production of activated carbon from Luscar char: Experimental and modeling studies. Microp. Mesop. Mat., 85, 3, 219-225. https:// doi.org/10.1016/j.micromeso.2005.06.018

Brand-Williams, W., Cuvelier, M. E., Berset, C. (1995). Use of a free radical method to evaluate antioxidant activity. LWT - Food Sci. Technol., 28(1), 25-30. https://doi. org/10.1016/S0023-6438(95)80008-5

Carrera, C., Ruiz-Rodríguez, A., Palma, M., Barroso, C. G. (2012). Ultrasound assisted extraction of phenolic compounds from grapes. Anal. Chim. Acta, 732, 100-104. https://doi.org/10.1016/j.aca.2011.11.032

Chaves, J. O., de Souza, M. C., da Silva, L. C., Lachos-Perez, D., Torres-Mayanga, P. C., Machado, A. P. da F., ..., Rostagno, M. A. (2020). Extraction of flavonoids from natural sources using modern techniques. Front. Chem., 8. https://doi.org/10.3389/fchem.2020.507887

Chemat, F., Rombaut, N., Sicaire, A.-G., Meullemiestre, A., Fabiano-Tixier, A.-S., Abert-Vian, M. (2017). Ultrasound assisted extraction of food and natural products. Mechanisms, techniques, combinations, protocols and applications. A review. Ultrasonics Sonochem., 34, 540560. https://doi.org/10.1016/j.ultsonch.2016.06.035

Chemat, F., Zill-e-Huma, Khan, M. K. (2011). Applications of ultrasound in food technology: Processing, preservation 
Quispe, M. A., Valenzuela, J. A. P., de la Cruz, A. R. H., Silva, C. R. E., Quiñonez, G. H., Cervantes, G. M. M. (2021). Optimization of ultrasound-assisted extraction of polyphenols from globe artichoke (Cynara scolymus L.) bracts residues using response surface methodology. Acta Sci. Pol. Technol. Aliment., 20(3), 277-290. http://dx.doi.org/10.17306/J.AFS.2021.0937

and extraction. Ultrasonics Sonochem., 18(4), 813-835. https://doi.org/10.1016/j.ultsonch.2010.11.023

D’Antuono, I., Carola, A., Sena, L. M., Linsalata, V., Cardinali, A., Logrieco, A. F., ..., Apone, F. (2018). Artichoke polyphenols produce skin anti-age effects by improving endothelial cell integrity and functionality. Molecules, 23(11), 1-13. https://doi.org/10.3390/molecules 23112729

Derringer, G., Suich, R. (1980). Simultaneous optimization of several response variables. J. Quality Technol., 12, 4, 214219. https://doi.org/10.1080/00224065.1980.11980968

FAOSTAT (2018). Production quantities of Artichokes by country. Retrieved from: http://www.fao.org/faostat/en/ \#data/QC/visualize

Flores, E. A., Villanueva, L. E. (2019). Análisis de la comercialización y exportación de alcachofa producida en Junín a Estados Unidos, periodo (2011-2013). Anál. Científic., 80(2), 328-342. Retrieved from https://revistas.lamolina.edu.pe/index.php/acu/article/view/1447

Frutos, M. J., Ruiz-Cano, D., Valero-Cases, E., Zamora, S. (2019). Artichoke (Cynara scolymus L.). In S. M. Nabavi, A. S. Silva, Nonvitamin and nonmineral nutritional supplements (pp. 135-138). Academic Press. https://doi. org/10.1016/B978-0-12-812491-8.00018-7

Jiménez-Moreno, N., Cimminelli, M. J., Volpe, F., Ansó, R., Esparza, I., Mármol, I., ..., Ancín-Azpilicueta, C. (2019). Phenolic composition of artichoke waste and its antioxidant capacity on differentiated Caco-2 cells. Nutrients, 11(8). https://doi.org/10.3390/nu11081723

Kollia, E., Markaki, P., Zoumpoulakis, P., Proestos, C. (2017). Antioxidant activity of Cynara scolymus L. and Cynara cardunculus L. extracts obtained by different extraction techniques. Nat. Prod. Res., 31(10), 1163-1167. https://doi.org/10.1080/14786419.2016.1219864

Mahboubi, M. (2018). Cynara scolymus (artichoke) and its efficacy in management of obesity. Bull. Fac. Pharm. Cairo Univ., 56(2), 115-120. https://doi.org/10.1016/j. bfopcu.2018.10.003

Maran, J. P. (2017). Ultrasound assisted extraction of bioactive compounds from Nephelium lappaceum L. fruit peel using central composite face centered response surface design. Arab. J. Chem., 10, S1145-S1157. https:// doi.org/10.1016/j.arabjc.2013.02.007

Maran, J. P., Mekala, V., Manikandan, S. (2018). Modeling and optimization of ultrasound-assisted extraction of polysaccharide from Cucurbita moschata. Carbohydr. Polym., 92(2), 2018-2026. https://doi.org/10.1016/j. carbpol.2012.11.086

Maran, J. P., Sivakumar, V., Sridhar, R., Immanuel, V. P. (2013). Development of model for mechanical prop- erties of tapioca starch based edible films. Ind. Crops Prod., 42, 159-168. https://doi.org/10.1016/j.indcrop. 2012.05.011

Mena-García, A., Rodríguez-Sánchez, S., Ruiz-Matute, A. I., Sanz, M. L. (2020). Exploitation of artichoke byproducts to obtain bioactive extracts enriched in inositols and caffeoylquinic acids by Microwave Assisted Extraction. J. Chromatogr., A, 1613. https://doi.org/10.1016/j.chroma.2019.460703

Negro, D., Montesano, V., Grieco, S., Crupi, P., Sarli, G., De Lisi, A., Sonnante, G. (2012). Polyphenol compounds in artichoke plant tissues and varieties. J. Food Sci., 77(2), C244-C252. https://doi.org/10.1111/j.17503841.2011.02531.x

Noriega-Rodríguez, D., Soto-Maldonado, C., Torres-Alarcón, C., Pastrana-Castro, L., Weinstein-Oppenheimer, C., Zúñiga-Hansen, M. E. (2020). Valorization of globe artichoke (Cynara scolymus) agro-industrial discards, obtaining an extract with a selective eect on viability of cancer cell lines. Processes, 8(6). https://doi. org/10.3390/pr8060715

Rabelo, R. S., MacHado, M. T. C., Martínez, J., Hubinger, M. D. (2016). Ultrasound assisted extraction and nanofiltration of phenolic compounds from artichoke solid wastes. J. Food Eng., 178, 170-180. https://doi. org/10.1016/j.jfoodeng.2016.01.018

Rezende, Y. R. R. S., Nogueira, J. P., Narain, N. (2017). Comparison and optimization of conventional and ultrasound assisted extraction for bioactive compounds and antioxidant activity from agro-industrial acerola (Malpighia emarginata DC) residue. LWT - Food Sci. Technol., 85, 158-169. https://doi.org/10.1016/j. lwt.2017.07.020

Rice-Evans, C. A., Miller, N. J., Paganga, G. (1996). Structure-antioxidant activity relationships of flavonoids and phenolic acids. Free Rad. Biol. Med., 20(7), 933-956.

Ruiz-Cano, D., Pérez-Llamas, F., Frutos, M. J., Arnao, M. B., Espinosa, C., López-Jiménez, J. Á., ..., Zamora, S. (2014). Chemical and functional properties of the different by-products of artichoke (Cynara scolymus L.) from industrial canning processing. Food Chem., 160, 134140. https://doi.org/10.1016/j.foodchem.2014.03.091

Sałata, A., Gruszecki, R., Dyduch, J. (2012). Morphological and qualitative characterization of globe artichoke $(\mathrm{Cy}$ nara scolymus L.) cultivars 'Symphony' and 'Madrigal' on depending of the heads growth. Acta Sci. Pol., Hortorum Cultus, 11(5), 67-80. Retrieved from http://www. hortorumcultus.actapol.net/pub/11_5_67.pdf

Salem, M. B., Affes, H., Ksouda, K., Dhouibi, R., Sahnoun, Z., Hammami, S., Zeghal, K. M. (2015). Pharmacological 
studies of artichoke leaf extract and their health benefits. Plant Foods Hum. Nutr., 70(4), 441-453. https://doi. org/10.1007/s11130-015-0503-8

Scalbert, A., Manach, C., Morand, C., Rémésy, C., Jiménez, L. (2005). Dietary polyphenols and the prevention of diseases. Crit. Rev. Food Sci. Nutr., 45(4), 287-306. https://doi.org/10.1080/1040869059096

Singleton, V. L., Rossi, J. A. (1965). Colorimetry of total phenolics with phosphomolybdic-phosphotungstic acid reagents. Am. J. Enol. Viticult., 16, 144-158.

Soria, A. C., Villamiel, M. (2010). Effect of ultrasound on the technological properties and bioactivity of food: A review. Trends Food Sci. Technol., 21(7), 323-331. https://doi.org/10.1016/j.tifs.2010.04.003

Sun, T., Ho, C. T. (2005). Antioxidant activities of buckwheat extracts. Food Chem., 90(4), 743-749. https://doi. org/10.1016/j.foodchem.2004.04.035

Tiwari, B. K., Donnell, C. P. O., Cullen, P. J. (2009). Effect of sonication on retention of anthocyanins in blackberry juice. J. Food Eng., 93(2), 166-171. https://doi. org/10.1016/j.jfoodeng.2009.01.027

Wang, L., Weller, C. L. (2006). Recent advances in extraction of nutraceuticals from plants. Trends Food Sci. Technol., 17, 6, 300-312. https://doi.org/10.1016/j.tifs. 2005.12.004
Zardo, I., de Espíndola Sobczyk, A., Marczak, L. D. F., Sarkis, J. (2017). Optimization of ultrasound assisted extraction of phenolic compounds from sunflower seed cake using response surface methodology. Waste Biomass Valor., 10, 33-44. https://doi.org/10.1007/s12649017-0038-3

Zhang, R. F., Zhang, F. X., Zhang, M. W., Wei, Z. C., Yang, C. Y., Zhang, Y., ..., Chi, J. W. (2011). Phenolic composition and antioxidant activity in seed coats of 60 chinese black soybean (Glycine max L. Merr.) varieties. J. Agric. Food Chem., 59(11), 5935-5944. https://doi. org/10.1021/jf201593n

Zhang, Y.-L., Cao, F. (2015). Fine particulate matter $\left(\mathrm{PM}_{2.5}\right)$ in China at a city level. Sci. Rep., 5. Art. 14884 (2015). https://doi.org/10.1038/srep14884

Zuorro, A., Maffei, G., Lavecchia, R. (2014). Effect of solvent type and extraction conditions on the recovery of phenolic compounds from artichoke waste. Chem. Eng. Trans., 39, 463-468. https://doi.org/10.3303/ CET1439078

Zuorro, A., Maffei, G., Lavecchia, R. (2016). Reuse potential of artichoke (Cynara scolimus L.) waste for the recovery of phenolic compounds and bioenergy. J. Cleaner Prod., 111, 279-284. https://doi.org/10.1016/j. jclepro.2015.06.011 